\title{
Efficacy and Safety of a Fixed Combination of Irbesartan/ Hydrochlorothiazide in Chinese Patients with Moderate to Severe Hypertension
}

\author{
Qi-Fang Huang $\cdot$ Chang-Sheng Sheng $\cdot$ Yan Li • \\ Gen-Shan Ma • Qiu-Yan Dai · Ji-Guang Wang • \\ on behalf of the INCENT Investigators
}

Published online: 20 April 2013

(c) The Author(s) 2013. This article is published with open access at Springerlink.com

\begin{abstract}
Background and Objectives In a multi-center, single-arm, prospective study, we investigated the efficacy and safety of the fixed irbesartan/hydrochlorothiazide combination in Chinese patients with moderate to severe hypertension.

Methods Eligible patients were aged 18-75 years, with a blood pressure of 160-199 mmHg systolic or 100-119 mmHg diastolic during a 1-week wash-out phase off antihypertensive medication. The enrolled patients started antihypertensive treatment with irbesartan/hydrochlorothiazide $150 \mathrm{mg} /$ $12.5 \mathrm{mg}$ once daily, with the possible addition of irbesartan $150 \mathrm{mg}$ once daily and up-titration to irbesartan/hydrochlorothiazide $300 \mathrm{mg} / 25 \mathrm{mg}$ once daily at 4 and 8 weeks of follow-up, respectively. The primary efficacy variable was the goal blood pressure-attaining rate at 12 weeks of follow-up $(<140 / 90 \mathrm{mmHg}$, or $<130 / 80 \mathrm{mmHg}$ in patients with diabetes mellitus).

Results In the intention-to-treat analysis $(n=501)$ at 12 weeks of follow-up, the goal blood pressure-attaining rate was $57.3 \%$, and the mean change in blood pressure
\end{abstract}

Clinical trial registration number (ClinicalTrials.gov): NCT00670566.

Q.-F. Huang · C.-S. Sheng · Y. Li · J.-G. Wang $(\square)$

The Centre for Epidemiological Studies and Clinical Trials,

The Shanghai Institute of Hypertension, Ruijin Hospital,

Shanghai Jiaotong University School of Medicine,

Ruijin 2nd Road 197, Shanghai 200025, China

e-mail: jiguangw@gmail.com

G.-S. Ma

Department of Cardiology, Zhongda Hospital,

Southeast University, Nanjing, China

Q.-Y. Dai

Department of Cardiology, Shanghai First People's Hospital,

Shanghai Jiaotong University, Shanghai, China from baseline was $27.8 \mathrm{mmHg}$ [ $95 \%$ confidence interval (CI) 26.4-29.1 mmHg; $p<0.001]$ systolic and $13.5 \mathrm{mmHg}$ (95 \% CI 12.6-14.4 mmHg; $p<0.001)$ diastolic. Similar findings were observed in the per-protocol analysis $(n=449)$. The prevalence of microalbuminuria and left ventricular hypertrophy significantly $(p \leq 0.01)$ decreased from $33.4 \%(150 / 449)$ and $50.4 \%(215 / 427)$ at baseline to $23.4 \%(105 / 447)$ and $41.3 \%(176 / 427)$ at the end of follow-up, respectively. Four patients $(2.0 \%)$ reported a serious adverse event.

Conclusion The fixed irbesartan/hydrochlorothiazide combination may control blood pressure to the target level in about $60 \%$ of Chinese patients with moderate to severe hypertension, with an acceptable safety profile.

\section{Introduction}

While the number of hypertensive patients is increasing in most countries because of longevity and unhealthy lifestyles, the control rate of hypertension remains low in many countries, such as China. According to the 2002 China National Nutrition and Health Survey, the prevalence of hypertension was $18.8 \%$ among persons aged over 18 years, whereas the control rate of hypertension was only $6.2 \%$ [1]. One of the major reasons for the low control rate is that the currently recommended antihypertensive drugs usually target one pathogenic pathway of hypertension and are sufficiently efficacious only in a fraction of hypertensive patients, even at high dosages [2, 3]. Combining two or more classes of antihypertensive drugs with complementary mechanisms might increase the blood pressure-lowering efficacy in specific patients and increase the number of patients who would have a significant response to antihypertensive therapy $[2,3]$. Because a 
fixed-dose combination in a single pill is probably an efficient approach to combination therapy, several singlepill combination drugs have been recently developed and are increasingly used in the management of hypertension in many countries, including China.

The combined use of an angiotensin receptor blocker and a thiazide diuretic is considered a preferred combination by most of the current guidelines [3-5]. This class of fixed-combination drugs has been extensively studied in Europe $[6,7]$ and North America [8-11]. However, there is still very limited clinical trial data in the Chinese population. The fixed irbesartan/hydrochlorothiazide combination became available in the Chinese market in $2004[12,13]$ and is currently the most commonly prescribed agent in its class in China. In this multi-center, single-arm, prospective study, we investigated the efficacy and safety of the fixed irbesartan/hydrochlorothiazide combination in Chinese patients with moderate to severe hypertension.

\section{Methods}

\subsection{Study Design}

The present study was designed as a multi-center, openlabel, single-arm, prospective trial and was conducted from April 2008 to February 2009 in 18 hospitals across China. The study protocol was approved by the ethics committee of Ruijin Hospital, Shanghai Jiaotong University School of Medicine (Shanghai, China) and, as necessary, also by the ethics committees of the participating hospitals. All patients gave written informed consent.

The study consisted of a 1-week wash-out phase and a subsequent 12-week study treatment period. The 1-week wash-out phase included one screening visit at the beginning and one visit at the end for determination of eligibility. The 12-week study treatment period included four visits at $2,4,8$, and 12 weeks of follow-up. At each of these clinic visits, blood pressure - as the major determining factor for inclusion in the study and the major efficacy variable of the study-was measured three times consecutively after at least $5 \mathrm{~min}$ of rest in the sitting position in the morning between 08:00 and 10:00 $\mathrm{h}$, using a validated automated blood pressure monitor (HEM 7071; Omron Healthcare, Kyoto, Japan). These three blood pressure readings 30 to $60 \mathrm{~s}$ apart were averaged for clinical decisions and for the present analysis. When the arm circumference was larger than $32 \mathrm{~cm}$, a larger cuff was used.

If, at the screening visit, previously untreated patients had a blood pressure of $160-199 \mathrm{mmHg}$ systolic or $100-119 \mathrm{mmHg}$ diastolic, and if patients previously treated with antihypertensive monotherapy had a blood pressure of $140-179 \mathrm{mmHg}$ systolic or $90-109 \mathrm{mmHg}$ diastolic and had discontinued their previous antihypertensive monotherapy, they could enter the wash-out phase for determination of eligibility. After the wash-out run-in phase, eligible patients entered the 12 -week study treatment period and started taking irbesartan/hydrochlorothiazide $150 \mathrm{mg} / 12.5 \mathrm{mg}$ once daily. A tablet of irbesartan $150 \mathrm{mg}$ and an additional tablet of irbesartan/hydrochlorothiazide $150 \mathrm{mg} / 12.5 \mathrm{mg}$ could be added at 4 and 8 weeks of follow-up, respectively, for systolic/diastolic blood pressure to reach the target level of $<140 / 90 \mathrm{mmHg}$, or $<130 /$ $80 \mathrm{mmHg}$ in patients with diabetes mellitus. The study medication could also be stopped in the presence of symptomatic hypotension or any other serious adverse events related to the study medication. The purpose of the clinic visit at 2 weeks of follow-up was to assure the safety of and patient compliance with antihypertensive therapy. It was decided that the study medication should not change at 2 weeks of follow-up, unless such a change was necessary. Patients were instructed to take the study medication between 08:00 and 10:00 $\mathrm{h}$ every morning except on the day of the clinic visit, when the medication was administered after blood pressure had been measured. Other antihypertensive agents or drugs with a potential blood pressure-lowering or blood pressure-increasing action were not to be used during the 12-week study treatment period. The study medication was supplied free of charge for the whole study period by Sanofi China (Shanghai, China).

\subsection{Study Population}

Eligible patients were men and women aged 18-75 years, with a blood pressure of $160-199 \mathrm{mmHg}$ systolic or 100-119 mmHg diastolic at the clinic visit at the end of the 1 -week wash-out phase. The exclusion criteria for the study were as follows: blood pressure $\geq 200 \mathrm{mmHg}$ systolic or $\geq 120 \mathrm{mmHg}$ diastolic; secondary hypertension; women who were pregnant, lactating, or of childbearing potential without proper contraception; cardiac diseases including cardiomyopathy, valvular heart disease, heart failure, or documented left ventricular ejection fraction reduction $(<45 \%)$; severe arrhythmias such as ventricular or supraventricular arrhythmia, pre-excitation syndrome, seconddegree or third-degree atrioventricular block and sick sinus syndrome; and other significant, uncontrolled, or lifethreatening conditions or diseases. We also excluded patients with a serum concentration of alanine or aspartate transaminase $\geq 2$ times the upper normal limits; a serum creatinine concentration $\geq 176.8 \mu \mathrm{mol} / \mathrm{l}$; creatinine clearance or an estimated glomerular filtration rate $<30 \mathrm{ml} / \mathrm{min}$ per $1.73 \mathrm{~m}^{2}$; albuminuria $\geq 2+$ on a dipstick test; gout or serum uric acid $\geq 406 \mu \mathrm{mol} / 1$ in men or $\geq 348 \mu \mathrm{mol} / 1$ in women; a serum potassium concentration $<3.5 \mathrm{mmol} / \mathrm{l}$ or $\geq 5.5 \mathrm{mmol} / \mathrm{l} ;$ or uncontrolled diabetes mellitus, as 
diagnosed by a plasma fasting glucose concentration $>11.0 \mathrm{mmol} / \mathrm{l}$ or a plasma glycosylated hemoglobin concentration $>8.5 \%$; and patients who were taking antidepressant medication or were allergic to the study medication.

The following diseases or conditions did not lead to exclusion: a history of stroke (excluding transient ischemic attack) at least 6 months prior to inclusion; the presence of coronary heart disease (a documented coronary atherosclerosis or stenosis); evidence of arrhythmia (on an electrocardiogram); dyslipidemia (a serum total cholesterol concentration $\geq 6.22 \mathrm{mmol} / \mathrm{l}$, low-density lipoprotein cholesterol $\geq 4.14 \mathrm{mmol} / \mathrm{l}$, or triglycerides $\geq 2.26 \mathrm{mmol} / \mathrm{l}$, or use of statins); controlled diabetes mellitus (a fasting plasma glucose concentration from 7.1 to $11.0 \mathrm{mmol} / \mathrm{l}$ or on oral antidiabetic drugs or insulin); and chronic kidney disease (albuminuria or a serum creatinine concentration from 132.6 to $176.8 \mu \mathrm{mol} / \mathrm{l}$ in men and 123.8 to $176.8 \mu \mathrm{mol} / \mathrm{l}$ in women).

\subsection{Efficacy and Safety Evaluations}

The primary efficacy variable was the goal blood pressureattaining rate at the end of the 12-week study. The goal blood pressure was defined as a systolic/diastolic blood pressure of $<140 / 90$ or $<130 / 80 \mathrm{mmHg}$ in the absence or presence of diabetes mellitus, respectively.

Secondary efficacy variables included changes from baseline in systolic and diastolic blood pressure at 4,8 , and 12 weeks of follow-up, and in the echocardiographically measured left ventricular mass and urinary albumin excretion as measured on a first morning void urine sample at 12 weeks of follow-up. We defined left ventricular hypertrophy as a left ventricular mass index of at least $112 \mathrm{~g} / \mathrm{m}^{2}$ in men and $105 \mathrm{~g} / \mathrm{m}^{2}$ in women, and microalbuminuria as a urinary albumin-to-creatinine ratio of at least $2.5 \mathrm{mg} / \mathrm{mmol}$ in men and $3.5 \mathrm{mg} / \mathrm{mmol}$ in women.

All adverse events were documented for information on symptoms, severity, relation to the study medication, intervention, and outcome. Routine biochemical tests of blood and urine were performed for clinical laboratory safety evaluations. Any clinically significant changes in physical examinations or laboratory findings were recorded as adverse events.

\subsection{Statistical Analysis}

We performed intention-to-treat and per-protocol analyses in all patients who entered the study treatment period and in the patients who completed the 12-week study on study drugs, respectively. The safety analysis was performed in all patients who had ever started the study treatment. Continuous and categorical variables were analyzed using the Student's $t$ test and $\chi^{2}$ test, respectively. Normality of distributions was evaluated by the Shapiro-Wilk statistic. Analysis of changes from baseline in blood pressure and other continuous efficacy or safety variables was performed by the paired $t$ test if they were normally distributed and by the Wilcoxon signed rank test if they were not normally distributed. We performed multiple logistic regression to study factors associated with the use of high-dose antihypertensive medication. We performed subgroup analyses according to sex (men vs. women), age ( $\geq 55$ years vs. $<55$ years), body mass index ( $\geq 25 \mathrm{~kg} / \mathrm{m}^{2}$ vs. $<25 \mathrm{~kg} / \mathrm{m}^{2}$ ), and the presence and absence of isolated systolic hypertension (systolic blood pressure $\geq 160 \mathrm{mmHg}$ and diastolic blood pressure $<90 \mathrm{mmHg}$ ), diabetes mellitus, and chronic kidney disease.

\section{Results}

\subsection{Patient Characteristics}

Of the 632 screened patients, 501 were enrolled in the study and started treatment with irbesartan/hydrochlorothiazide $150 \mathrm{mg} / 12.5 \mathrm{mg}$ once daily. During the 12-week study treatment period, 52 patients $(10.4 \%)$ were withdrawn because they withdrew their consent $(n=18$, $3.6 \%)$, did not follow the study protocol $(n=5,1.0 \%)$, because of adverse events $(n=13,2.5 \%)$, or other reasons $(n=16,3.2 \%)$. In total, 449 patients completed the 12-week study follow-up.

Table 1 shows the baseline characteristics of the 501 patients by sex [264 (52.7\%) were women]. Compared with the women, the men were slightly younger $(-1.8$ years; $p=0.03)$, had lower systolic blood pressure $(-1.9 \mathrm{mmHg} ; p=0.05)$, had higher diastolic blood pressure $(+3.0 \mathrm{mmHg} ; p<0.0001)$ and hence narrower pulse pressure $(-4.9 \mathrm{mmHg} ; p<0.0001)$, and included more users of antihypertensive drugs $(p=0.02)$ and antidiabetic drugs $(p=0.03)$. However, the men and women were similar in most baseline characteristics such as the body mass index; pulse rate; presence of diabetes mellitus, dyslipidemia, or chronic kidney disease; previous history of stroke; and previous use of specific classes of antihypertensive drugs $(p>0.05)$.

In the intention-to-treat analysis $(n=501)$, during the study treatment period, the dosage of the study medication remained at $150 \mathrm{mg} / 12.5 \mathrm{mg}$ of irbesartan/hydrochlorothiazide per day in 313 patients $(62.5 \%)$ and increased to $300 \mathrm{mg} / 12.5 \mathrm{mg}$ and to $300 \mathrm{mg} / 25 \mathrm{mg}$ of irbesartan/ hydrochlorothiazide per day in 111 patients $(22.2 \%)$ and 77 patients $(15.3 \%)$, respectively. In the per-protocol analysis $(n=449)$, the corresponding numbers of patients were $272(60.6 \%), 105(23.4 \%)$, and $72(16.0 \%)$, respectively. 
Table 1 Baseline characteristics of the patients included in the intention-to-treat analysis

\begin{tabular}{|c|c|c|c|}
\hline Characteristic & $\begin{array}{l}\text { Men } \\
(n=237)\end{array}$ & $\begin{array}{l}\text { Women } \\
(n=264)\end{array}$ & $p$ value \\
\hline Age (years; mean \pm SD) & $54.1 \pm 9.8$ & $55.9 \pm 8.6$ & 0.03 \\
\hline $\begin{array}{l}\text { Body mass index }\left(\mathrm{kg} / \mathrm{m}^{2}\right. \\
\text { mean } \pm \mathrm{SD})\end{array}$ & $25.8 \pm 3.1$ & $25.7 \pm 3.5$ & 0.77 \\
\hline $\begin{array}{l}\text { Systolic blood pressure } \\
\quad(\mathrm{mmHg} ; \text { mean } \pm \mathrm{SD})\end{array}$ & $161.5 \pm 11.3$ & $163.4 \pm 10.0$ & 0.05 \\
\hline $\begin{array}{l}\text { Diastolic blood pressure } \\
\quad(\mathrm{mmHg} ; \text { mean } \pm \mathrm{SD})\end{array}$ & $99.5 \pm 8.6$ & $96.5 \pm 8.4$ & 0.0001 \\
\hline $\begin{array}{l}\text { Pulse rate (beats/min; } \\
\text { mean } \pm \text { SD) }\end{array}$ & $74.7 \pm 9.7$ & $74.1 \pm 10.1$ & 0.46 \\
\hline \multicolumn{4}{|c|}{ Previous or concomitant disease $[n(\%)]$} \\
\hline Stroke $^{\mathrm{a}}$ & $3(1.2)$ & $1(0.4)$ & 0.27 \\
\hline Coronary heart disease $\mathrm{e}^{\mathrm{b}}$ & $5(2.1)$ & $14(5.3)$ & 0.06 \\
\hline Arrhythmia $^{c}$ & $12(5.1)$ & $9(3.4)$ & 0.36 \\
\hline Dyslipidemia $^{\mathrm{d}}$ & $4(1.7)$ & $9(3.4)$ & 0.23 \\
\hline Diabetes mellitus ${ }^{\mathrm{e}}$ & $35(14.8)$ & $50(18.9)$ & 0.21 \\
\hline Chronic kidney disease ${ }^{f}$ & $77(32.5)$ & $98(37.1)$ & 0.28 \\
\hline \multicolumn{4}{|l|}{ Previous treatment $[n(\%)]^{\mathrm{g}}$} \\
\hline Antihypertensive treatment & $117(49.4)$ & $158(59.9)$ & 0.02 \\
\hline Calcium channel blockers & $52(21.9)$ & $70(26.5)$ & 0.23 \\
\hline $\begin{array}{l}\text { Angiotensin-converting } \\
\text { enzyme inhibitors }\end{array}$ & $29(12.2)$ & $32(12.1)$ & 0.97 \\
\hline Angiotensin receptor blockers & 27 (11.4) & $25(9.5)$ & 0.48 \\
\hline$\beta$-Blockers & $5(2.1)$ & $11(4.2)$ & 0.19 \\
\hline Diuretics & $5(3.0)$ & $9(3.4)$ & 0.38 \\
\hline Other antihypertensive drugs & $12(5.1)$ & $27(10.2)$ & 0.03 \\
\hline Aspirin & $4(1.7)$ & $3(1.1)$ & 0.60 \\
\hline Statins & $1(0.4)$ & $1(0.4)$ & 0.94 \\
\hline Antidiabetic drugs & $4(1.7)$ & $14(5.3)$ & 0.03 \\
\hline
\end{tabular}

${ }^{a}$ Excluding transient ischaemic attack

b Defined as a documented coronary atherosclerosis or stenosis

c Arrhythmia evidenced by an electrocardiogram

${ }^{\mathrm{d}}$ Defined as a serum concentration of at least $6.22 \mathrm{mmol} / \mathrm{l}$ total cholesterol, $4.14 \mathrm{mmol} / 1 \mathrm{low}$-density lipoprotein cholesterol, or $2.26 \mathrm{mmol} / \mathrm{l}$ triglycerides, or as the use of statins

e Defined as a fasting plasma glucose concentration from 7.1 to $11.0 \mathrm{mmol} / \mathrm{l}$, or as the use of antidiabetic drugs or insulin

${ }^{\mathrm{f}}$ Defined as albuminuria or a serum creatinine concentration from 132.6 to $176.8 \mu \mathrm{mol} / \mathrm{l}$ in men and from 123.8 to $176.8 \mu \mathrm{mol} / 1$ in women

${ }^{\mathrm{g}}$ Use of drugs during the 2 weeks prior to the screening visit

\subsection{Antihypertensive Efficacy}

In the intention-to-treat analysis, the irbesartan/hydrochlorothiazide combination therapy reduced systolic/diastolic blood pressure from $162.5 / 97.9 \mathrm{mmHg}$ at baseline to 138.7/86.4, 135.6/84.3, 134.2/83.9, and 134.7/84.4 mmHg at $2,4,8$, and 12 weeks of follow-up, respectively (Fig. 1).

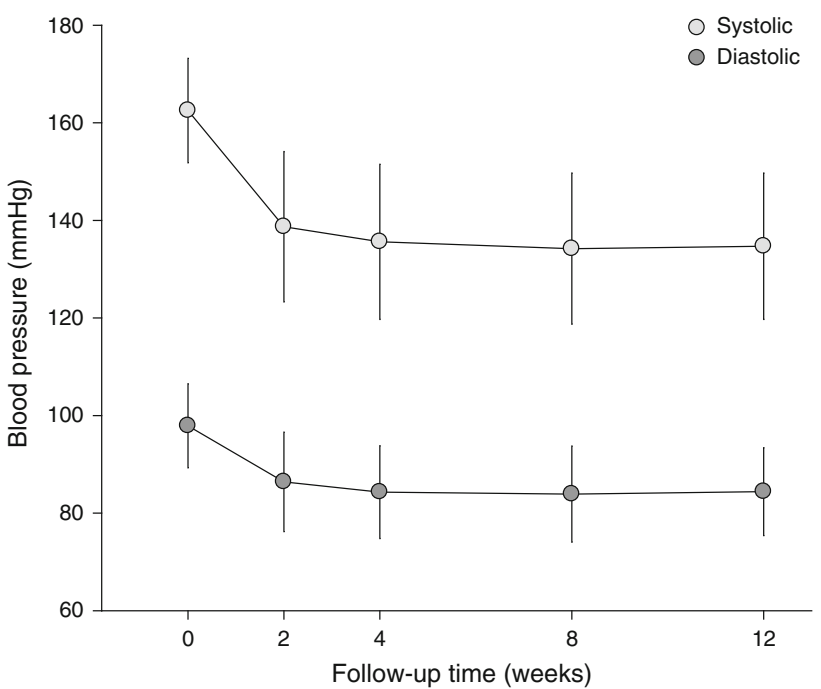

Fig. 1 Systolic and diastolic blood pressure at baseline and during follow-up in the intention-to-treat analysis. The vertical lines denote the standard deviations of the mean systolic and diastolic blood pressure values

The mean changes from baseline in systolic/diastolic blood pressure were $-23.8 /-11.6 \mathrm{mmHg},-26.8 /-13.6 \mathrm{mmHg}$, $-28.2 /-14.0 \mathrm{mmHg}$, and $-27.8 /-13.5 \mathrm{mmHg}$ at $2,4,8$, and 12 weeks of follow-up, respectively (Fig. 2).

At 12 weeks of follow-up, the percentage of patients who attained the goal systolic/diastolic blood pressure $(<140 /$ $90 \mathrm{mmHg}$, or $<130 / 80 \mathrm{mmHg}$ in patients with diabetes mellitus) was $57.3 \%$ (Table 2). The goal blood pressureattaining rates in patients treated with irbesartan/hydrochlorothiazide $150 \mathrm{mg} / 12.5 \mathrm{mg}$ per day $(n=313), 300 \mathrm{mg} /$ $12.5 \mathrm{mg}$ per day $(n=111)$, and $300 \mathrm{mg} / 25 \mathrm{mg}$ per day $(n=77)$ were $68.1,53.2$, and $19.5 \%$, respectively. If the goal systolic/diastolic blood pressure was defined as $140 / 90 \mathrm{mmHg}$ in diabetic as well as nondiabetic patients, the goal blood pressure-attaining rates were $66.1 \%$ in all subjects and $77.0,62.2$, and $27.3 \%$ in patients treated with irbesartan/hydrochlorothiazide $150 \mathrm{mg} / 12.5 \mathrm{mg}(n=313)$, $300 \mathrm{mg} / 12.5 \mathrm{mg}$ per day $(n=111)$, and $300 \mathrm{mg} / 25 \mathrm{mg}$ per day $(n=77)$, respectively (Table 2; Fig. 3).

In the per-protocol analysis, similar findings were observed with regard to blood pressure changes from baseline and the percentages of patients who achieved the goal blood pressure (Table 2; Fig. 3).

\subsection{Determinants of Antihypertensive Efficacy}

In multiple logistic regression analysis of the intention-totreat study sample, we identified male sex [odds ratio (OR) $1.73,95 \%$ confidence interval (CI) 1.16-2.56; $p=0.007]$ and baseline systolic blood pressure $(+10 \mathrm{mmHg}$; OR 
1.59, $95 \%$ CI 1.31-1.92; $p<0.0001)$ and diastolic blood pressure $(+5 \mathrm{mmHg}$; OR $1.17,95 \%$ CI 1.04-1.32; $p=0.007)$ as significant factors associated with the use of high dosage of irbesartan/hydrochlorothiazide. In further intention-to-treat analysis, we studied the blood pressure changes from baseline and the percentage of patients who achieved the goal blood pressure at the end of follow-up, while accounting for various baseline characteristics (Table 3$)$. The goal blood pressure $(<140 / 90 \mathrm{mmHg})-$ attaining rate was significantly lower in overweight and obese patients than in normal-weight subjects (59.6 vs. $75.1 \% ; p \leq 0.0003)$ and significantly lower in patients with chronic kidney disease than in those with normal renal function (53.1 vs. $73.0 \% ; p \leq 0.0003$ ).

\subsection{Left Ventricular Hypertrophy} and Microalbuminuria

In the per-protocol analysis, the irbesartan/hydrochlorothiazide combination therapy significantly reduced the prevalence of albuminuria $(n=449)$ by $30 \%(95 \%$ CI $12-46 ; p=0.004$ ) from $33.4 \%$ at baseline to $23.4 \%$ at the end of follow-up, and significantly reduced the prevalence of left ventricular hypertrophy $(n=427)$ by $19 \%$ (95\% CI $4-32 ; p=0.01$ ) from $50.4 \%$ to $41.3 \%$ over the same period.

\subsection{Safety}

Of the 501 patients who started treatment with the irbesartan/hydrochlorothiazide combination, $163 \quad(32.5 \%)$ reported at least one adverse event. Table 4 shows adverse events with an incidence $>1 \%$ and those typically relevant to the use of irbesartan/hydrochlorothiazide combination therapy. Hyperuricemia was the most frequent $(n=23$, $4.6 \%)$ of the 77 adverse events $(15.4 \%)$ that were related to the study medication. A total of 4 serious adverse events $(0.8 \%)$ in 4 patients were reported, including 1 hemorrhagic stroke, 1 hypertensive emergency, 1 hypertensive urgency, and 1 spinal disc herniation. None of these serious adverse events led to death.

\section{Discussion}

Our study showed that fixed irbesartan/hydrochlorothiazide combination therapy administered in a dosage range of $150 \mathrm{mg} / 12.5 \mathrm{mg}$ to $300 \mathrm{mg} / 25 \mathrm{mg}$ once daily may control systolic/diastolic blood pressure to a level below $140 / 90 \mathrm{mmHg}$ in approximately two thirds of Chinese patients with moderate to severe hypertension. Increasing the dose of irbesartan/hydrochlorothiazide in $40 \%$ of patients might substantially increase the goal blood
Fig. 2 Mean changes from baseline in systolic and diastolic blood pressure in the intentionto-treat analysis

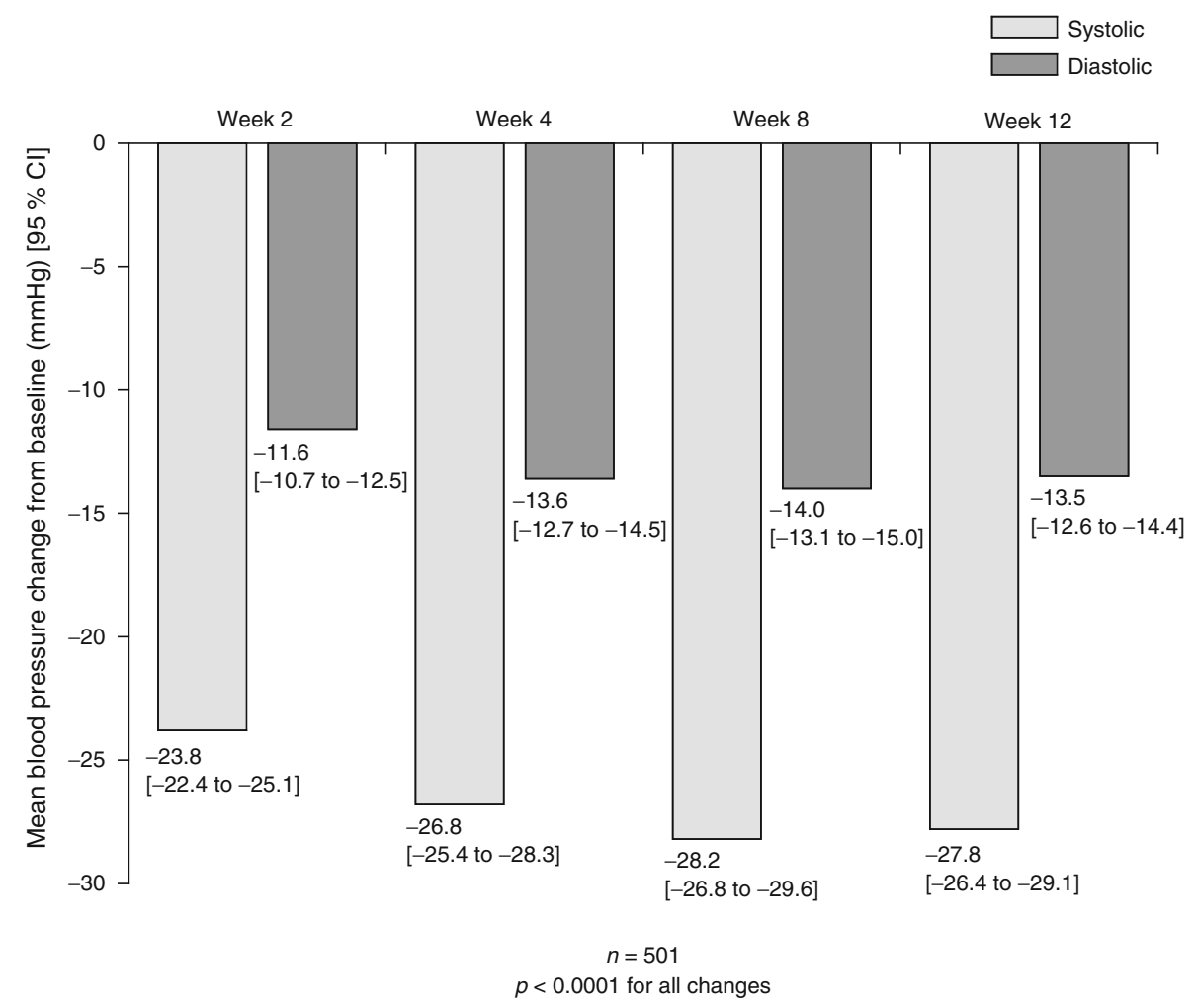


Table 2 Percentages of patients who attained the goal blood pressure

\begin{tabular}{llllr}
\hline Rate of attainment of goal blood pressure & \multicolumn{3}{l}{ Follow-up time (weeks) } \\
\cline { 2 - 4 } & 2 & 4 & 8 & 12
\end{tabular}

Intention-to-treat analysis $(n=501)$

Goal blood pressure $<140 / 90 \mathrm{mmHg}$, or $<130 / 80 \mathrm{mmHg}$ in diabetic patients (\%)

Goal blood pressure $<140 / 90 \mathrm{mmHg}(\%)$

Per-protocol analysis $(n=449)$

Goal blood pressure $<140 / 90 \mathrm{mmHg}$, or $\quad 42.8 \quad 60.5 \quad 65.3 \quad 62.6$ $<130 / 80 \mathrm{mmHg}$ in diabetic patients $(\%)$

Goal blood pressure $<140 / 90 \mathrm{mmHg}(\%)$

$\begin{array}{llll}49.2 & 67.9 & 72.5 & 72.2\end{array}$

pressure-attaining rate from 48.1 to $66.1 \%$ of all enrolled patients. Even if the goal blood pressure was defined as a systolic/diastolic pressure of $<130 / 80 \mathrm{mmHg}$ in patients with diabetes, the rate of control of hypertension was still nearly $60 \%$.

Our finding is in line with the results of the INCLUSIVE (Irbesartan/Hydrochlorothiazide Blood Pressure Reductions in Diverse Patient Populations) trial, which was conducted as a multi-center, prospective, open-label, single-arm study in an American population [9]. The INCLUSIVE trial consisted of four periods: $4-5$ weeks of placebo, 2 weeks of hydrochlorothiazide $12.5 \mathrm{mg}$ /day, and 8 weeks each of irbesartan/hydrochlorothiazide $150 \mathrm{mg} /$ $12.5 \mathrm{mg}$ and $300 \mathrm{mg} / 25 \mathrm{mg}$ per day, respectively. In the intention-to-treat analysis, the blood pressure-lowering efficacy was evaluated in 736 patients for the total 18-week study treatment period from commencement of hydrochlorothiazide to the end of the trial. The mean changes from baseline in systolic/diastolic blood pressure were 15.1/7.2 and 21.5/10.4 mmHg at 10 and 18 weeks of follow-up, respectively. The corresponding rates of attainment of goal blood pressure $(<140 / 90$, or $<130 / 80 \mathrm{mmHg}$ in patients with diabetes) were 48 and $69 \%$, respectively. The slightly higher rate of attainment of goal blood pressure in the INCLUSIVE trial than in our study (69 vs. $57.3 \%$ ) may be attributable to the forced titration of combination therapy in a large majority of the enrolled patients and the inclusion of patients with mild hypertension in the INCLUSIVE trial [9].

Our observation in subgroup analysis is also in keeping with the results of various subgroup analyses of the INCLUSIVE trial [14]. In the INCLUSIVE trial, the rate of attainment of goal blood pressure was similar across different ethnicities $(70 \%$ in Caucasians, $66 \%$ in African Americans, and $65 \%$ in Hispanics) [15], similar in older and younger patients ( $72 \%$ in patients aged $\geq 65$ years and $68 \%$ in those aged $<65$ years) [16], and similar in patients with and without isolated systolic hypertension (systolic blood pressure control in 74 vs. $81.6 \%$ ) [17], but slightly lower in men than in women (60 vs. $76 \%$ ) [18], slightly
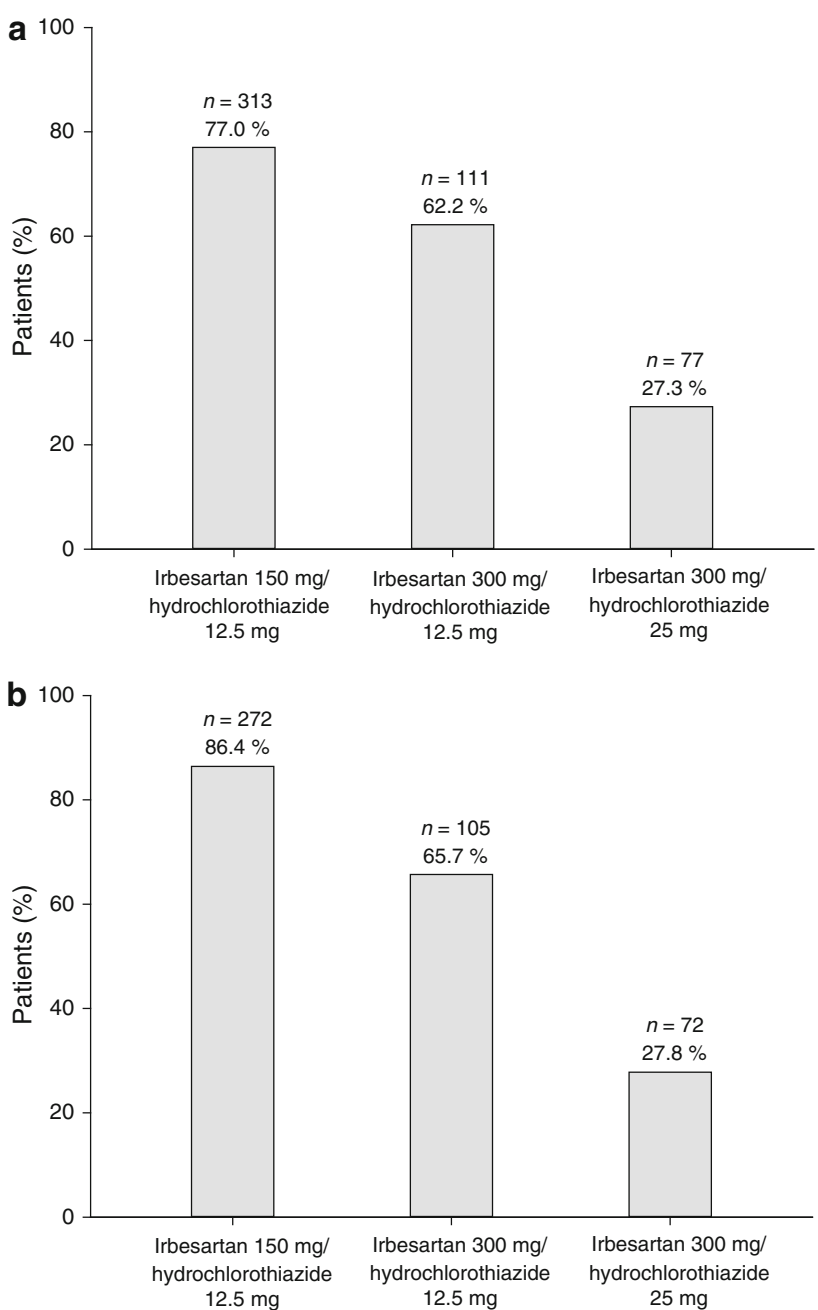

Fig. 3 Percentage of patients who achieved the goal blood pressure $(<140 / 90 \mathrm{mmHg})$ at various dosages: a intention-to-treat analysis; b per-protocol analysis

lower in overweight and obese patients than in normalweight patients (66.7 vs. $82.5 \%$ ) [19], and (taking into account the lower goal blood pressure thresholds in patients with diabetes), slightly lower in diabetic patients than in nondiabetic patients (40.1 vs. $81.7 \%)[19,20]$.

Our findings should also be compared with the results of a previous Chinese study, which studied the efficacy and safety of the fixed irbesartan/hydrochlorothiazide $150 \mathrm{mg} / 12.5 \mathrm{mg}$ combination in 926 patients with mild to moderate hypertension (diastolic blood pressure $90-109 \mathrm{mmHg}$ and systolic blood pressure $<180 \mathrm{mmHg}$ ) [13]. In the per-protocol analysis $(n=920)$ of that 8 -week, multi-center, single-arm, prospective study, 637 patients $(69 \%), 211$ patients (22.9\%), and 72 patients $(7.8 \%)$ used irbesartan/hydrochlorothiazide $150 \mathrm{mg} / 12.5 \mathrm{mg}, 300 \mathrm{mg} / 12.5 \mathrm{mg}$, and $300 \mathrm{mg} / 25 \mathrm{mg}$ per day, respectively. The irbesartan/hydrochlorothiazide combination therapy reduced systolic/diastolic blood pressure by $22 / 16 \mathrm{mmHg}$ from $149 / 95 \mathrm{mmHg}$ at 
Table 3 Subgroup analysis on the blood pressure-lowering efficacy in the intention-to-treat analysis

\begin{tabular}{|c|c|c|c|c|c|c|c|c|c|}
\hline \multirow[t]{3}{*}{ Parameter } & \multirow[t]{3}{*}{$n$} & \multicolumn{4}{|c|}{ Change in blood pressure } & \multicolumn{4}{|c|}{ Rate of attainment of goal blood pressure } \\
\hline & & \multicolumn{2}{|l|}{ Systolic } & \multicolumn{2}{|l|}{ Diastolic } & \multicolumn{2}{|c|}{$<140 / 90 \mathrm{mmHg}$} & \multicolumn{2}{|c|}{$\begin{array}{l}<130 / 80 \mathrm{mmHg} \text { (in diabetic } \\
\text { patients) }\end{array}$} \\
\hline & & $\mathrm{mmHg} ;$ mean $\pm \mathrm{SD}$ & $p$ value & mmHg; mean $\pm \mathrm{SD}$ & $p$ value & Patients $(\%)$ & $p$ value & Patients (\%) & $p$ value \\
\hline \multicolumn{10}{|l|}{ Sex } \\
\hline Male & 237 & $-26.6 \pm 15.1$ & 0.07 & $-13.7 \pm 10.9$ & 0.59 & 63.7 & 0.29 & 54.0 & 0.16 \\
\hline Female & 264 & $-28.8 \pm 15.8$ & & $-13.3 \pm 10.1$ & & 68.2 & & 60.2 & \\
\hline \multicolumn{10}{|l|}{ Age } \\
\hline$<55$ years & 246 & $-28.3 \pm 15.4$ & 0.75 & $-15.9 \pm 9.6$ & $<0.0001$ & 68.3 & 0.30 & 59.8 & 0.27 \\
\hline$\geq 55$ years & 255 & $-27.3 \pm 15.6$ & & $-11.2 \pm 10.8$ & & 63.9 & & 54.9 & \\
\hline \multicolumn{10}{|c|}{ Body mass index } \\
\hline$<25 \mathrm{~kg} / \mathrm{m}^{2}$ & 209 & $-29.4 \pm 15.0$ & 0.10 & $-14.1 \pm 10.5$ & 0.30 & 75.1 & 0.0003 & 64.1 & 0.009 \\
\hline$\geq 25 \mathrm{~kg} / \mathrm{m}^{2}$ & 292 & $-26.6 \pm 15.7$ & & $-13.0 \pm 10.5$ & & 59.6 & & 52.4 & \\
\hline \multicolumn{10}{|c|}{ Isolated systolic hypertension ${ }^{\mathrm{a}}$} \\
\hline No & 414 & $-28.0 \pm 15.7$ & 0.97 & $-15.8 \pm 9.5$ & $<0.0001$ & 66.4 & 0.71 & 58.0 & 0.5 \\
\hline Yes & 87 & $-26.9 \pm 14.7$ & & $-2.65 \pm 8.0$ & & 64.4 & & 54.0 & \\
\hline \multicolumn{10}{|c|}{ Diabetes mellitus ${ }^{\mathrm{b}}$} \\
\hline No & 416 & $-27.0 \pm 15.3$ & 0.007 & $-13.7 \pm 10.5$ & 0.30 & 65.1 & 0.33 & 65.1 & $<0.0001$ \\
\hline Yes & 85 & $-31.3 \pm 15.8$ & & $-12.4 \pm 10.2$ & & 70.6 & & 18.8 & \\
\hline \multicolumn{10}{|c|}{ Left ventricular hypertrophy ${ }^{\mathrm{c}}$} \\
\hline No & 233 & $-27.2 \pm 14.6$ & 0.34 & $-13.4 \pm 10.3$ & 0.87 & 66.5 & 0.71 & 57.9 & 0.72 \\
\hline Yes & 245 & $-28.4 \pm 16.4$ & & $-13.6 \pm 11.0$ & & 64.9 & & 56.3 & \\
\hline \multicolumn{10}{|c|}{ Chronic kidney disease $^{\mathrm{d}}$} \\
\hline No & 326 & $-28.7 \pm 14.1$ & 0.07 & $-13.6 \pm 10.3$ & 0.77 & 73.0 & $<0.0001$ & 62.6 & 0.001 \\
\hline Yes & 175 & $-26.0 \pm 17.7$ & & $-13.3 \pm 10.9$ & & 53.1 & & 47.4 & \\
\hline
\end{tabular}

baseline to $127 / 79 \mathrm{mmHg}$ at 8 weeks of follow-up. In that previous study, which included patients with mild hypertension, $6.7 \%$ of patients reported adverse events [13].

Our study should be interpreted within the context of its limitations. The evaluation of blood pressure-lowering efficacy relied mainly on blood pressure measurement in the clinic. We did not perform ambulatory blood pressure monitoring nor other hemodynamic investigations. Another major limitation of our study was its noncomparative design. Without a proper control group, placebo effects, observer bias, and regression to the mean may influence the evaluation of blood pressure-lowering efficacy. However, observations in noncomparative studies, such as the amplitude of changes in blood pressure from baseline and the rate of attainment of goal blood pressure, are similar to those in routine clinical practice. Despite the noncomparative design of our study, our findings are also in keeping with observations in the irbesartan/hydrochlorothiazide combination arms of controlled studies [21-26]. In those studies, the fixed irbesartan/hydrochlorothiazide combination alone normalized blood pressure in 51.4 and $50.2 \%$ of patients with hypertension previously uncontrolled by monotherapy who were receiving clinic blood pressure monitoring $(<140 / 90 \mathrm{mmHg})$ or home blood pressure monitoring $(<135 / 85 \mathrm{mmHg})$, respectively [7, 21], and also in $53.4 \%$ of patients with moderate hypertension [10] and in $34.6 \%$ of patients with severe hypertension [11, $22]$. In addition, those studies also confirmed that the blood pressure-lowering efficacy of the fixed irbesartan/hydrochlorothiazide combination was largely independent of sex [21], age [21, 23, 24], and methods of blood pressure measurement [6-8]; slightly less prominent in obese or diabetic patients [23-25]; and more prominent in patients with a higher initial blood pressure [23, 26].

In line with the results of previous studies [27, 28], the safety data from our study demonstrated that the irbesartan/ hydrochlorothiazide combination was well tolerated even at the high dose, and was associated with few and mild 
Table 4 Adverse events in the safety dataset $(n=501)$

\begin{tabular}{lll}
\hline Adverse event $^{\mathrm{a}}$ & $\begin{array}{l}\text { Patients } \\
{[n(\%)]}\end{array}$ & $\begin{array}{l}\text { Events possibly related to the } \\
\text { study medication }[n(\%)]\end{array}$ \\
\hline $\begin{array}{l}\text { Dizziness } \\
\text { Hyperuricemia }\end{array}$ & $\begin{array}{l}25(8.2) \\
\text { Headache }\end{array}$ & $\begin{array}{l}(1)(2.2) \\
23(4.6)\end{array}$ \\
$\begin{array}{l}\text { Upper respiratory tract } \\
\text { infection }\end{array}$ & $6(1.2)$ & 0 \\
Severe hypertension & $5(1.0)$ & $4(0.8)$ \\
Palpitation & $5(1.0)$ & $3(0.6)$ \\
Fatigue & $5(1.0)$ & $2(0.4)$ \\
Elevation of alanine or & $4(0.8)$ & $3(0.6)$ \\
$\quad$ aspartate transaminase & & \\
Hypokalemia & $3(0.6)$ & $2(0.4)$ \\
Hyperkalemia & $1(0.2)$ & $1(0.2)$ \\
Gout & $1(0.2)$ & $1(0.2)$ \\
Total & $163(32.5)$ & $77(15.4)$
\end{tabular}

a The adverse events reported in this table are those with an incidence $>1 \%$ and those relevant to the use of irbesartan/hydrochlorothiazide combination therapy

adverse events. Hyperuricemia was the most frequently recorded adverse event. Nonetheless, gout was reported in only one patient.

\section{Conclusion}

The fixed irbesartan/hydrochlorothiazide combination may control blood pressure to the target level in about $60 \%$ of Chinese patients with moderate or severe hypertension, with an acceptable safety profile. These blood pressure changes are clinically important in the protection of target organs and in the prevention of cardiovascular events, as evidenced by the significant changes in the prevalence of left ventricular hypertrophy and albuminuria observed in our short-term follow-up study.

Acknowledgments The authors gratefully acknowledge the participation of the patients and the contribution of the investigators from 18 hospitals. The principal investigators (listed in the order of the number of enrolled patients) were Shou-Chun $\mathrm{Xu}$ from Beijing Aerospace 731 Hospital (50 patients); Gen-Shan Ma from Nanjing Zhongda Hospital of Southeast University (40 patients); Qiu-Yan Dai from Shanghai First People's Hospital (35 patients); Meng Wei from Shanghai Sixth People's Hospital (35 patients); Biao Xu from Nanjing Gulou Hospital (31 patients); Yu-Gang Dong from The First Affiliated Hospital of Sun Yat-Sen University, Guangzhou (28 patients); Jian Hu from The First Hospital of China Medical University, Shenyang (27 patients); Yong Huo from Beijing University First Hospital (27 patients); Guo-Sheng Fu from Hangzhou Shao Yi-Fu Hospital (27 patients); Yi Luo from Guangzhou First People's Hospital (26 patients); Wen-Ling Zhu from Beijing Union Medical College Hospital (26 patients); Shang-Lang Cai from The Affiliated Hospital of Qingdao University School of Medicine (25 patients); Li-
Sheng Liu from Beijing Hypertension League Institute (25 patients); Xin-Chun Yang from Beijing Chao-Yang Hospital (25 patients); Tao Guo from The First Affiliated Hospital of Kunming Medical College (17 patients); Ying-Ling Zhou from Guangdong Province General Hospital, Guangzhou (17 patients); and Yu-Hua Liao from Wuhan Union Hospital (14 patients). The study was funded and sponsored by Sanofi China (Shanghai). Dr. Wang reports receiving consulting and lecture fees from Sanofi China (Shanghai). The other authors declare no conflicts of interest.

Open Access This article is distributed under the terms of the Creative Commons Attribution Noncommercial License which permits any noncommercial use, distribution, and reproduction in any medium, provided the original author(s) and the source are credited. The exclusive right to any commercial use of the article is with Springer.

\section{References}

1. Wu Y, Huxley R, Li L, Anna V, Xie G, Yao C, Woodward M, Li X, Chalmers J, Gao R, Kong L, Yang X, China NNHS Steering Committee, China NNHS Working Group. Prevalence, awareness, treatment, and control of hypertension in China: data from the China National Nutrition and Health Survey 2002. Circulation. 2008;118:2679-86.

2. Palatini P. Combination therapy in the management of hypertension: focus on angiotensin receptor blockers combined with diuretics. J Clin Hypertens (Greenwich). 2005;7:96-101.

3. Gradman AH, Basile JN, Carter BL, Bakris GL, American Society of Hypertension Writing Group. Combination therapy in hypertension. J Clin Hypertens (Greenwich). 2011;13:146-54.

4. Mancia G, Laurent S, Agabiti-Rosei E, Ambrosioni E, Burnier M, Caulfield MJ, Cifkova R, Clément D, Coca A, Dominiczak A, Erdine S, Fagard R, Farsang C, Grassi G, Haller H, Heagerty A, Kjeldsen SE, Kiowski W, Mallion JM, Manolis A, Narkiewicz K, Nilsson P, Olsen MH, Rahn KH, Redon J, Rodicio J, Ruilope L, Schmieder RE, Struijker-Boudier HA, van Zwieten PA, Viigimaa M, Zanchetti A, European Society of Hypertension. Reappraisal of European guidelines on hypertension management: a European Society of Hypertension Task Force document. J Hypertens. 2009;27:2121-58.

5. Writing Group of the 2010 Chinese Guidelines for the Management of Hypertension. Chinese guidelines for the management of hypertension (in Chinese). Chin J Cardiol. 2010;2011(39): 579-616.

6. Coca A, Calvo C, Sobrino J, Gómez E, López-Paz JE, Sierra C, Bragulat E, de la Sierra A. Once-daily fixed-combination irbesartan $300 \mathrm{mg} /$ hydrochlorothiazide $25 \mathrm{mg}$ and circadian blood pressure profile in patients with essential hypertension. Clin Ther. 2003;25:2849-64.

7. Bobrie G, Delonca J, Moulin C, Giacomino A, Postel-Vinay N, Asmar R, COmparative Study of Efficacy of Irbesartan/HCTZ with Valsartan/HCTZ Using Home Blood Pressure Monitoring in the TreAtment of Mild-to-Moderate Hypertension (COSIMA) Investigators. A home blood pressure monitoring study comparing the antihypertensive efficacy of two angiotensin II receptor antagonist fixed combinations. Am J Hypertens. 2005;18:1482-8.

8. Neutel JM, Smith D. Ambulatory blood pressure comparison of the anti-hypertensive efficacy of fixed combinations of irbesartan/ hydrochlorothiazide and losartan/hydrochlorothiazide in patients with mild-to-moderate hypertension. J Int Med Res. 2005;33: 620-31. 
9. Neutel JM, Saunders E, Bakris GL, Cushman WC, Ferdinand KC, Ofili EO, Sowers JR, Weber MA, INCLUSIVE Investigators. The efficacy and safety of low- and high-dose fixed combinations of irbesartan/hydrochlorothiazide in patients with uncontrolled systolic blood pressure on monotherapy: the INCLUSIVE trial. J Clin Hypertens (Greenwich). 2005;7:578-86.

10. Neutel JM, Franklin SS, Lapuerta P, Bhaumik A, Ptaszynska A. A comparison of the efficacy and safety of irbesartan/HCTZ combination therapy with irbesartan and HCTZ monotherapy in the treatment of moderate hypertension. J Hum Hypertens. 2008;22:266-74.

11. Neutel JM, Franklin SS, Oparil S, Bhaumik A, Ptaszynska A, Lapuerta P. Efficacy and safety of irbesartan/HCTZ combination therapy as initial treatment for rapid control of severe hypertension. J Clin Hypertens (Greenwich). 2006;8:850-7; quiz 858-9.

12. Tang B, Zhu J, Cai N, Fan W, Sun N, Liu G, Ma H. Effect and safety of irbesartan/hydrochlorothiazide combination therapy on mild to moderate essential hypertension (in Chinese). Chin Circ J. 2004; 19:430-2.

13. Sun NL, Jing S, Chen J. The control rate of irbesartan/hydrochlorothiazide combination regimen in the treatment of Chinese patients with mild to moderate hypertension (in Chinese). Chin J Cardiol. 2005;33:618-21.

14. Saunders E, Cable G, Neutel J. Predictors of blood pressure response to angiotensin receptor blocker/diuretic combination therapy: a secondary analysis of the Irbesartan/Hydrochlorothiazide Blood Pressure Reductions in Diverse Patient Populations (INCLUSIVE) study. J Clin Hypertens (Greenwich). 2008; 10:27-33.

15. Ofili EO, Ferdinand KC, Saunders E, Neutel JM, Bakris GL, Cushman WC, Sowers JR, Weber MA. Irbesartan/HCTZ fixed combinations in patients of different racial/ethnic groups with uncontrolled systolic blood pressure on monotherapy. J Natl Med Assoc. 2006;98:618-26.

16. Cushman WC, Neutel JM, Saunders E, Bakris GL, Ferdinand KC, Ofili EO, Sowers JR, Madder R, Weber MA. Efficacy and safety of fixed combinations of irbesartan/hydrochlorothiazide in older vs younger patients with hypertension uncontrolled with monotherapy. Am J Geriatr Cardiol. 2008;17:27-36.

17. Chrysant SG, Neutel JM, Ferdinand KC. INCLUSIVE investigators. Irbesartan/hydrochlorothiazide for the treatment of isolated systolic hypertension: a subgroup analysis of the INCLUSIVE trial. J Natl Med Assoc. 2009;101:300-7.

18. Ofili EO, Cable G, Neutel JM, Saunders E. Efficacy and safety of fixed combinations of irbesartan/hydrochlorothiazide in hypertensive women: the INCLUSIVE trial. J Womens Health (Larchmt). 2008;17:931-8.

19. Lewin AJ, Weir MR. Antihypertensive efficacy and tolerability of irbesartan/hydrochlorothiazide in hypertensive patients stratified by body mass index and type 2 diabetes mellitus status: a post hoc subgroup analysis of the Irbesartan/HCTZ Blood Pressure Reductions in Diverse Patient Populations trial. Clin Ther. 2008; 30:2354-65.

20. Sowers JR, Neutel JM, Saunders E, Bakris GL, Cushman WC, Ferdinand KC, Ofili EO, Weber MA, INCLUSIVE Investigators. Antihypertensive efficacy of Irbesartan/HCTZ in men and women with the metabolic syndrome and type 2 diabetes. J Clin Hypertens (Greenwich). 2006;8:470-80.

21. Asmar R, Oparil S. Comparison of the antihypertensive efficacy of irbesartan/HCTZ and valsartan/HCTZ combination therapy: impact of age and gender. Clin Exp Hypertens. 2010;32:499-503.

22. Neutel JM, Franklin SS, Bhaumik A, Lapuerta P, Oparil S. Safety and tolerability of fixed-dose irbesartan/hydrochlorothiazide for rapid control of severe hypertension. Clin Exp Hypertens. 2009;31:572-84.

23. Franklin SS, Neutel JM. Efficacy and safety of irbesartan/HCTZ in severe hypertension according to cardiometabolic factors. J Clin Hypertens (Greenwich). 2010;12:487-94.

24. Weir MR, Neutel JM, Bhaumik A, De Obaldia ME, Lapuerta P. The efficacy and safety of initial use of irbesartan/hydrochlorothiazide fixed-dose combination in hypertensive patients with and without high cardiovascular risk. J Clin Hypertens (Greenwich). 2007;9(Suppl 5):23-30.

25. Neutel JM. A comparison of the efficacy and safety of irbesartan/ hydrochlorothiazide combination therapy with irbesartan monotherapy in the treatment of moderate or severe hypertension in diabetic and obese hypertensive patients: a post-hoc analysis review. Postgrad Med. 2011;123:126-34.

26. Franklin S, Lapuerta $P$, Cox D, Donovan M. Initial combination therapy with irbesartan/hydrochlorothiazide for hypertension: an analysis of the relationship between baseline blood pressure and the need for combination therapy. J Clin Hypertens (Greenwich). 2007;9(Suppl 5):15-22.

27. Bramlage P. Fixed combination of irbesartan and hydrochlorothiazide in the management of hypertension. Vasc Health Risk Manag. 2009;5:213-24.

28. Croxtall JD, Keating GM. Irbesartan/Hydrochlorothiazide: in moderate to severe hypertension. Drugs. 2008;68:1465-72. 